Laboratorio de Arte,3-1990 http://dx.doi.org/10.12795/LA.1990.i03.19

\title{
A PROPÓSITO DE DOS DIBUJOS DE VALDÉS LEAL
}

\author{
por EnRIQUe Valdivieso
}

Cuando en octubre de 1690, la muerte acabó con la actividad artística de Valdés Leal, el pintor se encontraba inmerso en la ejecución del programa iconográfico destinado a adornar los muros y bóvedas de la iglesia del Hospital de Venerables Sacerdotes de Sevilla. Este programa que en términos generales, incluye una exaltación del ministerio sacerdotal, pudo ser preparado ideológicamente por el canónigo don Justino de Neve que había sido el promotor de la construcción del edificio.

Dentro de este conjunto decorativo Valdés Leal alcanzó a realizar, si bien con la ayuda de su hijo Lucas, las pinturas de la bóveda y cúpula del presbiterio. A su muerte debía de tener preparados los dibujos que iban a servir el modelo para decorar los muros y bóvedas de la nave de la iglesia. Tal suposición parecía evidente al contemplar las pinturas existentes en los citados lugares, pues aunque presentan el estilo inferior y desmañado de su hijo Lucas, su organización compositiva y la expresividad de las figuras sugieren que están basados en ideas de superior categoría, elaborada por un talento creativo de mayor rango.

La identificación, ahora, de dos dibujos de Valdés Leal, que representan a San Ambrosio negando la entrada en el templo al Emperador Teodosio ${ }^{1}$, y El Concilio de Nicea $^{2}$, vienen a evidenciar que este artista, dejó resueltas las composiciones de las escenas situadas en la nave de la iglesia de los Venerables confirmándonos la suposición que anteriormente habíamos emitido ${ }^{3}$.

1. Figuró en la Exposición "Master Drawings, presented by Adolphe Stein". 6-18 julio 1981, Londres, Bury Street Gallery.

2. Museo del Louvre. Inventario de dibujos, $n .^{\circ} 18.473$.

3. Valdivieso, E.: Valdés Leal, Sevilla, 1988, p. 200. 
La composición del primer dibujo nos muestra que Valdés Leal concibió íntegramente en el dibujo preparatorio la descripción de la pintura definitiva realizada por su hijo Lucas, incluyendo la orla con sus inscripciones y fechas. Lucas Valdés en su versión mural, simplificó algunos detalles de la arquitectura del fondo de la escena y también limitó la gesticulación de alguno de los personajes, empobreciendo la idea original y rebajando la intensidad expresiva que emana del dibujo.

Las circunstancias de la ejecución de las pinturas de los Venerables permiten pensar que el dibujo corresponde a los últimos años de la actividad de Valdés Leal y que debió realizarlo hacia 1686, coincidiendo con los momentos en que se inició la decoración pictórica de esta iglesia.

Igual fecha puede aplicarse al segundo dibujo, El Concilio de Nicea aunque en esta ocasión falta la orla que rodea a todas las escenas de la nave de la iglesia, y también la cartela donde se identifica el episodio. A la magnífica soltura que evidencia Valdés leal en su dibujo, respondió su hijo Lucas con una versión mural de evidente debilidad técnica en la que dominan los elementos descriptivos en detrimento del vigor expresivo de la composición original. 


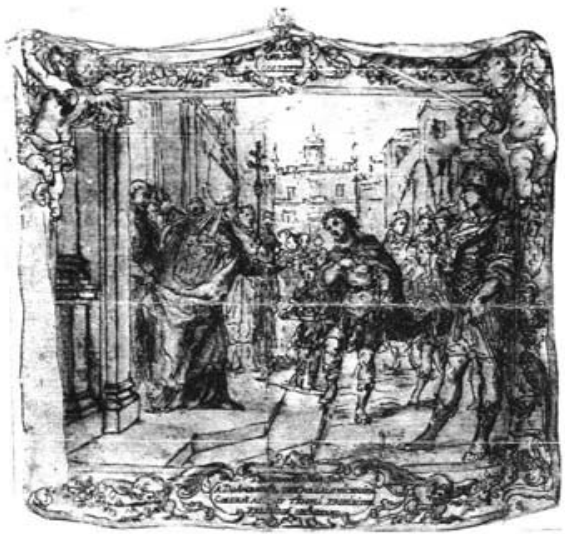

San Ambrosio negando la entrada en el templo al emperador Teodosio. Dibujo de Juan de Valdés Leal. Paris. Colección particular.

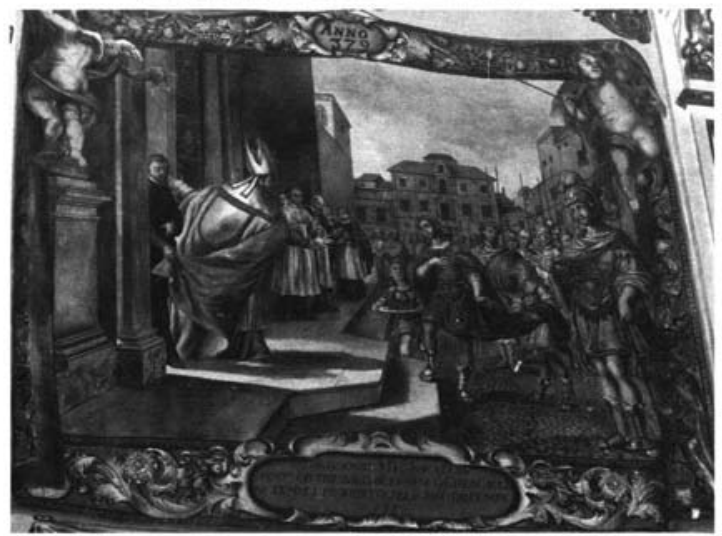

San Ambrosio negando la entrada en el templo al emperador Teodosio. Lucas Valdés. Sevilla. Iglesia del Hospital de Venerables Sacerdotes. 


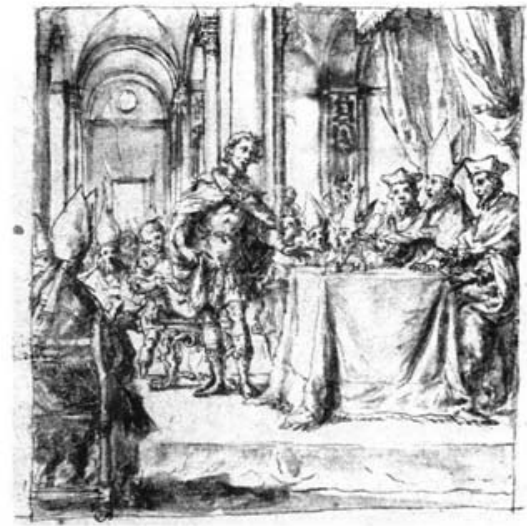

El Concilio de Nicea.

Dibujo de Juan de Valdés Leal. París. Museo del Louvre.

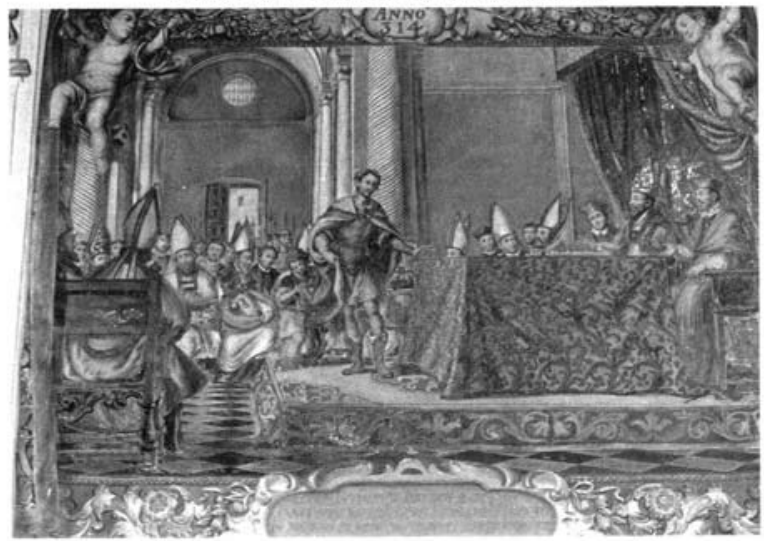

El Concilio de Nicea.

Pintura de Lucas Valdés. Sevilla. Iglesia del Hospital de Venerables Sacerdotes. 